\title{
MOTIVAÇÕES E RISCOS ASSOCIADOS A UM CENTRO \\ DE SERVIÇOS COMPARTILHADOS, TIPOS E MODELOS ORGANIZACIONAIS EXISTENTES, E O CASO DE UMA EMPRESA DE TECNOLOGIA E SERVIÇOS
}

\author{
Monique Ferreira Cavalcante ${ }^{1}$ \\ Marco Antonio Conejero ${ }^{2}$
}

CAVALCANTE, M. F.; CONEJERO, M. A. Motivações e riscos associados a um centro de serviços compartilhados, tipos e modelos organizacionais existentes, e o caso de uma empresa de tecnologia e serviços. Revista de Ciências Empresariais da UNIPAR, Umuarama, v. 22, n. 2, p. 221-245, jul./dez. 2021.

RESUMO: A criação de um Centro de Serviços Compartilhados (CSC) constitui uma estratégia amplamente adotada pelas organizações. O CSC faz parte da cadeia de valor da organização e pode ser definido como a concentração e compartilhamento das atividades de apoio na estrutura organizacional. $\mathrm{O}$ objetivo deste trabalho é discutir as motivações e riscos associados a um CSC, as estruturas organizacionais e modelos existentes de CSC na literatura e verificar no estudo de caso analisado, o tipo escolhido, com as vantagens e desvantagens apontadas. Para tanto, realizou-se uma pesquisa bibliográfica, o estudo de caso com pesquisa documental, observação participante, entrevistas semiestruturadas, e a triangulação dos dados do estudo de caso com a literatura existente. No caso analisado, dentre os ganhos identificados após a implementação do CSC, estão: redução de custos; agilidade na prestação do serviço; otimização dos processos; padronização e conformidade das atividades. Já em termos de tipos/modelos de CSC, a empresa A optou por um CSC do tipo intraorganizacional, back office e básico, e o modelo hierárquico baseado em departamento, sendo esse vinculado à Gerência de Administração. Essa vinculação gerou problemas relacionados à autonomia que é um dos atributos de um CSC.

PALAVRAS-CHAVE: Centro de Serviços Compartilhados; Motivações; Ganhos obtidos; Estrutura Organizacional; Estudo de Caso.

DOI: $\underline{10.25110 / \text { receu.v22i2.8580 }}$

${ }^{1}$ Programa de Pós-Graduação em Administração (PPGA) da Universidade Federal Fluminense (UFF) - Volta Redonda

${ }^{2}$ Programa de Pós-Graduação em Administração (PPGA) da Universidade Federal Fluminense (UFF) - Volta Redonda 


\title{
MOTIVATIONS AND RISKS ASSOCIATED WITH A SHARED SERVICE CENTER, EXISTING ORGANIZATIONAL TYPES AND MODELS, AND THE CASE OF A SERVICE \& TECHNOLOGY COMPANY
}

\begin{abstract}
The creation of a Shared Service Centre (SSC) is a strategy widely adopted by organizations. The SSC is part of the organization's value chain and can be defined as the concentration and sharing of supporting activities in the organizational structure. This paper aims at discussing the motivations and risks associated with an SSC, the existing organizational structures and models of SSC in the literature and to verify the chosen type in the case study being analysed, focusing on both the advantages and disadvantages. For this purpose, literature research was carried out, and the case study included documentary research, active observation, semi-structured interviews, and the triangulation of data from the case study with the existing literature. In the analysed case, the gains identified after the implementation of the SSC included cost reduction; agility in the provision of the service; optimization of processes; activity standardization and compliance. Regarding SSC types/models, company A opted for an SSC of the intraorganizational, back office and basic type, with a department-based hierarchical model, which is linked to the Administration Management. This linking generated problems related to autonomy, which is one of the attributes of an SSC.
\end{abstract}

KEYWORDS: Shared Service Centre; Motivations; Gains obtained; Organizational Structure; Case Study.

\section{MOTIVACIONES Y RIESGOS ASOCIADOS A UN CENTRO DE SERVICIOS COMPARTIDOS, TIPOS Y MODELOS ORGANIZATIVOS EXISTENTES Y EL CASO DE UNA EMPRESA DE TECNOLOGÍA Y SERVICIOS}

RESUMEN: La creación de un Centro de Servicios Compartidos (CSS) es una estrategia ampliamente adoptada por las organizaciones. La CSS es parte de la cadena de valor de la organización y puede definirse como la concentración y el intercambio de actividades de apoyo en la estructura organizativa. El objetivo de este trabajo es discutir las motivaciones y riesgos asociados a una CSS, las estructuras organizativas y modelos existentes de CSS en la literatura y verificar el tipo elegido en el caso de estudio analizado, con las ventajas y desventajas mencionadas. Para ello, se realizó una investigación bibliográfica, el estudio 
de caso con investigación documental, observación participante, entrevistas semiestructuradas y la triangulación de los datos del estudio de caso con la literatura existente. En el caso analizado, entre las ganancias identificadas luego de la implementación de la CSS, se encuentran: reducción de costos; agilidad en la prestación del servicio; optimización de procesos; estandarización y cumplimiento de actividades. En cuanto a tipos / modelos de CSC, la empresa A apostó por un CSC de tipo intraorganizacional, back office y básico, y el modelo jerárquico por departamento, que está vinculado a la Dirección de Administración. Esta vinculación generó problemas relacionados con la autonomía, que es uno de los atributos de un SSC.

PALABRAS CLAVE: Centro de Servicios Compartidos; Motivaciones; Ganancias obtenidas; Estructura Organizacional; Caso de Estudio.

\section{INTRODUÇÃO}

Durante os anos 70, as organizações utilizavam o modelo centralizado, especialmente nas funções de apoio. Na década seguinte surgiram as unidades estratégicas de negócios favorecendo o modelo descentralizado nessas funções, e cada unidade passou a ter autonomia para se organizar como desejasse. Isso causou multiplicidade de estruturas de suporte nas organizações, elevando os custos operacionais em diversas empresas, principalmente do setor automobilístico e elétrico (SCHULMAN et al., 2001). Foi nesse contexto que, ainda segundo esses autores, a General Eletric iniciou o modelo hoje conhecido como Centro de Serviços Compartilhados (CSC), sendo a pioneira na sua utilização.

Os CSCs podem ser definidos como concentração de recursos focados em atividades de apoio, ou áreas que optam pelo compartilhamento dessas atividades, ao invés de ter atividades rotineiras e cotidianas multiplicadas na estrutura da organização (SCHULMAN et al., 2001; QUINN, COOKE e KRIS, 2000).

A criação de um CSC constitui uma estratégia amplamente adotada pelas organizações. O CSC faz parte da cadeia de valor da organização, onde há uma redistribuição dos processos de negócios entre seus participantes, em busca de uma maior competitividade e produtividade (LOZINSKY, 2006). Alinhado com o conceito criado por Porter (1999) de cadeia de valor e suas atividades, Minnaar e Vosselman (2013) definem o CSC como atividades de apoio concentradas em uma estrutura centralizada para o atendimento das unidades de negócios.

Apesar de Minnar e Vosselman (2013) entenderem o CSC como uma estrutura centralizada, alguns autores entendem esse novo modelo como uma estrutura híbrida, ou seja, que possui características da estrutura centralizada 
e descentralizada (JANSSEN; JOHA, 2006; SCHULMAN et al., 2001). Essas contradições são frequentemente encontradas na literatura e há muitos modelos diferentes de CSCs (MAGALHÃES, 2018; QUINN; COOKE; KRIS, 2000). Diante disso, tem-se como problema de pesquisa as seguintes questões: Quais motivações e riscos estão associados à implementação de um CSC? Quais as vantagens e desvantagens associados aos diferentes tipos/ modelos organizacionais de CSC?.

O objetivo deste artigo é discutir as motivações e riscos associados a um CSC, as estruturas organizacionais e modelos existentes de CSC na literatura e verificar no estudo de caso analisado o tipo escolhido, com as vantagens e desvantagens apontadas.

$\mathrm{O}$ artigo está estruturado da seguinte forma: inicialmente é exposta a fundamentação teórica sobre CSC, conceito, motivações e riscos associados, os tipos existentes, seguido da metodologia utilizada. Na sequência são exibidas as discussões relacionadas ao estudo de caso e a conclusões com limitações e sugestões de estudos futuros. Por fim têm-se as referências bibliográficas utilizadas na pesquisa.

\section{REVISÃO BIBLIOGRÁFICA}

\subsection{Centro de Serviços Compartilhados}

Segundo Singh e Craike (2008), existe uma falta de consenso sobre o conceito de CSC. Por isso, eles realizaram um estudo com o objetivo de elucidar um conceito sólido que possa ser utilizado tanto por profissionais quanto pesquisadores. Associado a um CSC eles encontraram as seguintes dimensões chaves: a) Serviços compartilhados como a centralização das funções de suporte - a ideia é eliminar a duplicação de atividades de apoio que estão espalhadas pela organização. A centralização não precisa ocorrer num único local, mas precisa ser gerenciada centralmente para assegurar a continuidade dos processos; b) Serviços compartilhados como forma de explorar sinergias na prestação de serviços - gerar eficiência e redução de custos através da economia de escala. Sugestão de canais de prestação de serviços de maneira centralizada, agregando valor para a organização; c) Serviços compartilhados como agregação de funções de serviço interno - focar na concentração das funções como forma de melhoria da qualidade do serviço prestado; d) Serviços compartilhados como forma de preservar e explorar propriedade intelectual - gerenciar melhor as habilidades e o conhecimento da organização, utilizando essa expertise valiosa para outras organizações de forma empreendedora e flexível; e) Serviços compartilhados 
como veículo para futura terceirização - contrastando a dimensão 4 de comercialização do serviço, o enfoque nessa dimensão é a terceirização das atividades não essenciais.

A Figura 1 mostra o que ocorre com a organização quando a estratégia de CSC é adotada. Basicamente ao invés de se ter uma duplicidade de serviços oferecidos às distintas unidades de negócios do grupo empresarial, o CSC concentra todos os serviços de suporte aos clientes internos em uma unidade de estrutura organizacional, mas sem perder a qualidade e quantidade dos serviços oferecidos (JANSENN; JOHA, 2007).

Figura 1: Estratégia de um Centro de Serviços Compartilhados

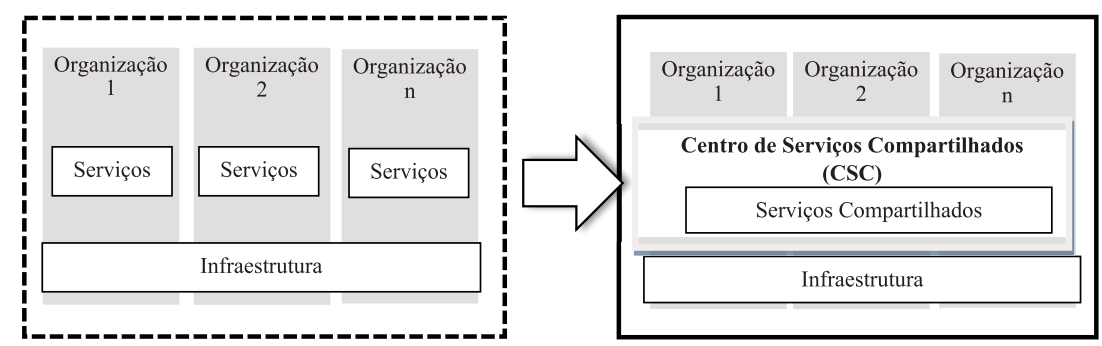

Fonte: Janssen e Joha (2007).

\subsection{Motivações e riscos associados à criação de um CSC}

Para essa seção, consideram-se como motivações, a oportunidade de trazer vantagens e benefícios, e como riscos, as situações que possam trazer desvantagens e limitações às organizações que visam criar um CSC.

Ulrich (1995) advertia que grande parte das organizações adotavam os CSCs sem conhecer afundo o que era ou quais eram os benefícios esperados. Globalização, ambientes de negócios, aumento da produtividade, reengenharia, exigência dos clientes internos, melhoria da qualidade, mudança organizacional, padronização dos processos e sistemas, delimitação das competências entre as áreas de apoio e de negócio, desenvolvimento tecnológico, redução de custos, controle e transparência dos custos, e flexibilidade são motivações das organizações que adotam os CSCs (JANSSEN; JOHA, 2006; MAGALHÃES, 2018; REILLY; WILLIAMS, 2003; SILVA; PEREIRA, 2004; ULRICH, 1995).

Complementando as motivações citadas, uma pesquisa realizada pela Deloitte (2017), elencou que as principais razões para a criação de um CSC são, entre outras, a permissão às demais áreas para focar em suas atividades primárias; a possibilidade de as organizações agilizarem as novas aquisições da 
área de compras; e a melhoria no estabelecimento de controles e compliance.

Algumas dessas motivações são diretamente conectadas e resultam em uma série de benefícios, como por exemplo, a oportunidade de acesso à tecnologia da informação de alta qualidade e habilidades técnicas que geram um melhor desempenho de equipe, segurança e compartilhamento de riscos (JANSSEN; JOHA, 2006). Outro exemplo é que com o agrupamento do desenvolvimento, da manutenção e do uso de serviços, os custos podem ser compartilhados, novas tecnologias podem ser viáveis e os níveis de serviços podem ser melhorados (JANSSEN; JOHA, 2006).

Há um estudo que classifica a motivação de criação de um CSC de acordo com dois fatores: (1) os que são relacionados à organização, como por exemplo, a redução de custos e a melhoria dos serviços prestados; e (2) os que são relacionados às unidades de negócio da empresa, como a economia de escala e a redução da necessidade de pessoal (BERGERON, 2003).

As razões para criação de um CSC também podem ser identificadas, segundo Schulman et al. (2001), através da eficiência (recursos agrupados, tecnologia de ponta e economia de escala) e a eficácia (padronização dos processos, conhecimento compartilhado e otimização do serviço). Os ganhos em eficiência ocorrem por etapas: redução do número de funcionários, redução de supervisão por meio do aumento do controle, melhoria dos sistemas e assim por diante, enquanto a eficácia acontece de forma linear, por meio de parcerias para a padronização de processos e correção de problemas de transferência de informações. Além disso, o compartilhamento do conhecimento entre os CSCs com a organização melhora a eficácia ao longo do tempo. Os ganhos de eficiência junto com a eficácia agregam valor para os clientes da empresa e os acionistas (SCHULMAN et al., 2001).

O National Audit Office (2007) do Reino Unido, que analisa os gastos públicos em nome do Parlamento com o objetivo de responsabilizar e melhorar o governo pelos seus serviços prestados, elaborou em 2007 um relatório sobre o CSC. O relatório, com o título de "Melhorando as funções corporativas utilizando o serviço compartilhado", apresenta os potenciais benefícios do CSC, alguns já vistos nessa seção, de uma forma mais detalhada e interligada, conforme ilustrado no Quadro 1. 
Quadro 1: Benefícios de um CSC

\begin{tabular}{|l|l|}
\hline Redução de custo & $\begin{array}{l}\text { Atingir economias de escala e altos níveis de } \\
\text { eficiência por meio da simplificação e padronização } \\
\text { de processos. }\end{array}$ \\
\hline $\begin{array}{l}\text { Baixo custo de } \\
\text { investimento }\end{array}$ & $\begin{array}{l}\text { A concentração de atividades transacionais de uma } \\
\text { organização em uma única operação de serviço } \\
\text { compartilhado faz uso mais eficiente do capital de } \\
\text { investido. }\end{array}$ \\
\hline $\begin{array}{l}\text { Melhores informações } \\
\text { e dados }\end{array}$ & $\begin{array}{l}\text { Altos níveis de investimento em tecnologia levam } \\
\text { a uma informação gerencial mais confiável, rica e } \\
\text { consistente, que possibilita mais redução de custo } \\
\text { financeiro, como, por exemplo, nas compras. }\end{array}$ \\
\hline Serviço ao cliente & $\begin{array}{l}\text { A partir de uma única localização, usando uma } \\
\text { melhor padronização de processos, é relativamente } \\
\text { fácil conseguir entregar serviços dentro de um } \\
\text { conjunto documentado de padrões de performance } \\
\text { com um foco explícito no cliente. }\end{array}$ \\
\hline Foco & $\begin{array}{l}\text { A agregação de processos transacionais libera tempo } \\
\text { para que os profissionais da área de operação possam } \\
\text { focar seu tempo em atividades de valor agregado. }\end{array}$ \\
\hline Comparabilidade & $\begin{array}{l}\text { A implementação de padrões comuns para toda a } \\
\text { organização possibilita uma melhor comparação } \\
\text { de performance e processos dentro de uma grande } \\
\text { organização. }\end{array}$ \\
\hline
\end{tabular}

Fonte: National Audit Office (2007).

A comparabilidade é um dos benefícios exibidos no Quadro 1, uma vez que a padronização dos processos em toda a organização proporciona a criação de métricas, mensuração dos serviços prestados, estabelecimento de metas e um possível desenvolvimento de carreira para incentivo dos colaboradores. Apesar do Quadro 1 indicar uma única localização como facilitadora do foco no cliente, o CSC possui a vantagem de unir os benefícios dos modelos centralizados e descentralizados, deixando para trás os principais impasses intrínsecos a esses modelos (SILVA et al., 2006).

Como desvantagens destacam-se, entre outros, a inflexibilidade na execução das atividades que foram padronizadas e o desgaste nas relações de trabalho devido às mudanças propostas (MAGALHÃES, 2018). Os impactos causados ao trabalhador são uma característica crítica do CSC, pois é difícil 
motivar o funcionário a trabalhar em uma área não estratégica e de baixo valor agregado (REILLY, 2000). Há também o risco do CSC não conseguir atender todas as necessidades de uma determinada unidade ou essa unidade sentir que outras unidades estão sendo privilegiadas, e começar a agir de forma independente do CSC desenvolvendo seus próprios serviços (JANSSEN; JOHA, 2006).

Os riscos englobam fatores relacionados aos custos; reprovação do modelo pelo cliente; colapsos ou falha na prestação do serviço; surgimento de tecnologias disruptivas que podem substituir um CSC inteiro; perda de produtividade e competitividade, caso não haja um acompanhamento na evolução dos padrões; competitividade com prestadores de serviços externos; gestão inapropriada; desaceleração econômica e problemas com fornecedores de solução (BERGERON, 2003). Além disso, o CSC possui as seguintes limitações (BERGERON, 2003):

- Choques culturais: a perda de alguns colegas de trabalho com a redução de pessoal; a nova forma de serviço ao cliente e a estrutura por recompensa impactarão a cultura organizacional, ocasionando uma inicial queda de eficiência;

- $\quad$ Perda do conhecimento: recrutamento de novos profissionais, pois os que detinham o conhecimento não estão mais no CSC (foram realocados em outras áreas ou buscaram novas empresas);

- Perda de controle: alguns gestores das unidades de negócio perderão as responsabilidades;

- Implicações legais: a auditoria e os acordos de nível de serviço, em conformidade com a organização e as leis, são requisitos para que o CSC permaneça funcionando;

- $\quad$ Necessidade de treinamento: CSC precisará de treinamentos sobre os princípios, foco no cliente, ferramentas de qualidade total, entre outros.

A mudança cultural nas organizações que optam pelo compartilhamento de serviços gera desafios para que os benefícios sejam atingidos, pois há uma resistência com relação à criação por parte dos gestores de unidades de negócios que costumavam centralizar e controlar a empresa (SILVA; PEREIRA, 2004). Nos estudos realizados para esse trabalho, pode-se perceber que a evidência da realidade desses benefícios nas organizações é mista, com organizações como a Ford e a GE obtendo ganhos (FORST, 2000), enquanto outras não tiveram tanto sucesso.

Com o intuito de facilitar o entendimento das motivações e riscos associados à criação de um CSC, foi elaborado o Quadro 2 com uma síntese dos 
fatores apresentados pelos autores.

Quadro 2: Síntese das Motivações e Riscos associados à criação de um CSC

\begin{tabular}{|c|c|c|c|}
\hline Motivações & Autores & Riscos & Autores \\
\hline $\begin{array}{l}\text { - } \text { Flexibilidade } \\
\text { - } \text { organizacional } \\
\text { - Melhor foco em seus } \\
\text { negócios principais } \\
\text { - Padronização dos } \\
\text { processos e dos sistemas } \\
\text { - Acesso a TI de alta } \\
\text { qualidade e habilidades } \\
\text { - Redução da necessidade } \\
\text { de pessoal } \\
\text { - Melhor desempenho de } \\
\text { equipe } \\
\text { - Produtividade } \\
\text { - Redução de custos } \\
\text { Melhoria da qualidade } \\
\text { dos serviços prestados } \\
\text { Melhoria no } \\
\text { estabelecimento de } \\
\text { controles e compliance } \\
\text { - Maior segurança e } \\
\text { compartilhamento de } \\
\text { riscos }\end{array}$ & $\begin{array}{l}\text { Bergeron (2003) } \\
\text { Deloitte (2017) } \\
\text { Janssen e Joha } \\
\text { (2006); } \\
\text { Reilly e } \\
\text { Williams (2003) } \\
\text { Schulman et al. } \\
\text { (2001) } \\
\text { Silva e Pereira } \\
\text { (2004) } \\
\text { Ulrich (1995) }\end{array}$ & $\begin{array}{l}\text { - Alto custo de } \\
\text { investimento } \\
\text { - Surgimento } \\
\text { de tecnologias } \\
\text { disruptivas } \\
\text { - Falta de } \\
\text { credibilidade por } \\
\text { parte dos clientes } \\
\text { - Incapacidade de } \\
\text { atendimento a } \\
\text { todas as demandas } \\
\text { solicitadas } \\
\text { - Inflexibilidade } \\
\text { na execução das } \\
\text { atividades que } \\
\text { foram padronizadas } \\
\text { - Desgaste nas } \\
\text { relações de trabalho } \\
\text { - Choques culturais } \\
\text { - Desmotivação do } \\
\text { funcionário } \\
\text { - Perda de } \\
\text { conhecimento } \\
\text { - Perda de } \\
\text { produtividade e } \\
\text { competitividade }\end{array}$ & $\begin{array}{l} \\
\\
\\
\\
\text { Bergeron } \\
\text { (2003) } \\
\text { Janssen e } \\
\text { Joha (2006) } \\
\text { Magalhães } \\
\text { (2018) } \\
\text { Reilly } \\
\text { (2000) }\end{array}$ \\
\hline
\end{tabular}

Fonte: Elaborado pelos autores.

\subsection{Estrutura Organizacional e Modelos de Centros de Serviços Compartilhados}

A posição do CSC na organização pode ser intraorganizacional ou interorganizacional. A figura 2 apresenta a diferença entre esses dois modelos. Quando há um compartilhamento entre departamentos de uma mesma organização, tem-se o modelo intraorganizacional, mas quando o compartilhamento ocorre entre duas ou mais organizações, o resultado é o modelo interorganizacional (JANSSEN; JOHA, 2006). 
Figura 2: Posição do modelo CSC

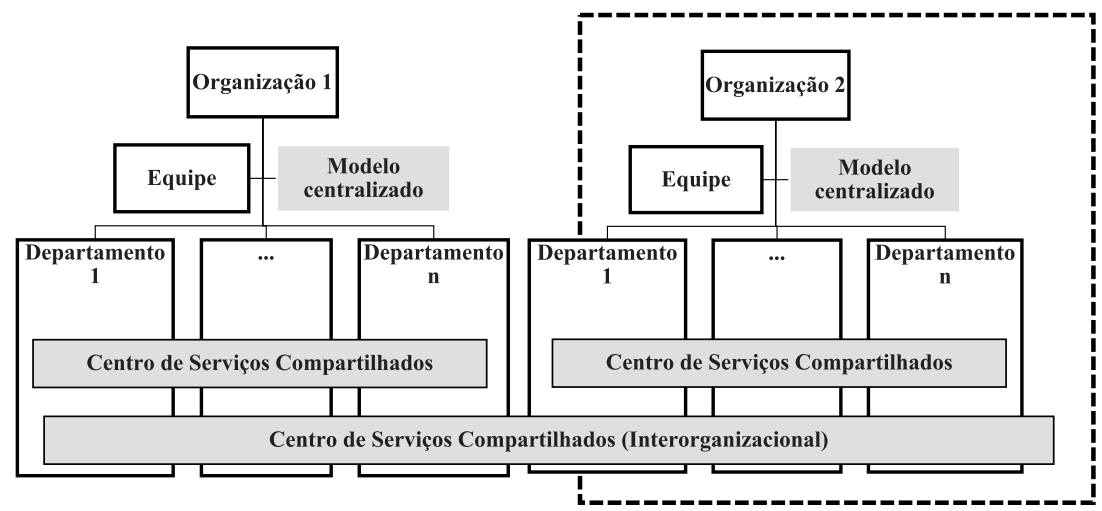

Fonte: Janssen e Joha (2006).

O modelo interorganizacional é mais utilizado nas administrações públicas e pode ser exemplificado pelas agências governamentais que, apesar de desenvolverem suas próprias atividades e sistemas de maneira independente, podem aderir ao CSC e serem vistas como um arranjo interno completo de governo que favorece a viabilidade das inovações (JANSSEN; JOHA, 2006). O modelo intraorganizacional é o mais comum e pode ser observado quando departamentos da mesma organização realizam compras juntos, por exemplo.

Conforme pode ser observado na figura 2, há ainda uma diferença a destacar, que é entre o modelo centralizado e o CSC intraorganizacional. No modelo centralizado, os processos são padronizados e executados em um único local físico para todos os departamentos. Este tipo de modelo oferece um alto controle no nível corporativo e economia de escala, mas o foco no cliente é baixo devido a sua posição centralizada (BERGERON, 2003).

Já o CSC intraorganizacional está posicionado perto dos clientes, e detêm certo grau de propriedade sobre a prestação do serviço (JANSSEN; JOHA, 2006). Ou seja, os processos não são padronizados e inflexíveis como acontece na centralização. Há uma troca contínua entre os clientes e o CSC, visto que na maioria das vezes os serviços que o CSC realiza são originados da área "dona" do processo (SCHULMAN et al., 2001).

Apesar da figura não evidenciar, deve-se discutir aqui a estrutura totalmente descentralizada, na qual cada departamento realiza o processo de apoio de forma rápida e flexível (BERGERON, 2003). É como se cada departamento realizasse suas compras de maneira independente, por exemplo. A estrutura 
descentralizada foca no cliente, mas gera um alto custo devido à multiplicidade de funções executando as mesmas atividades.

Para Ulbrich (2003), o CSC difere dos modelos centralizado e descentralizado. Ele entende que a centralização faz parte de uma organização com limitação nos conhecimentos dos serviços, enquanto na descentralização, os departamentos atuam na maioria das vezes de forma local e independente, mas com responsabilidades limitadas. Num arranjo de CSC, os processos e as atividades atendem a $100 \%$ da organização (ULBRICH, 2003). Além disso, segundo ele, o CSC atende entidades em outros locais e são organizados como autônomos.

O CSC é um modelo híbrido que deve combinar as vantagens da estrutura centralizada e descentralizada, resultando em economias de escala e escopo, e padronização, de um lado, e um alinhamento flexível e eficaz de TI com as necessidades do negócio, de outro (SCHULMANN et al., 2001; JANSSEN; JOHA, 2006).

Numa outra visão, o CSC é dividido em dois tipos: front office e back office. No primeiro, estão operações que requerem contato direto com o cliente, envolvendo tomada de decisão e alta competência. Enquanto no segundo estão operações que requerem pouco ou nenhum contato com o cliente, é relativo ao gerenciamento de tarefas que não são essenciais à atividade dos departamentos e podem ser organizadas em unidades separadas (PETRIŞOR; COZMIUC, 2016).

Quinn, Cooke e Kris (2000) mostram quatro tipos de CSC: básico, marketplace, marketplace avançado e empresa independente. A classificação avança do básico, que se constitui na formatação de uma unidade da própria organização, até o da empresa independente, que é uma empresa externa à organização (terceirização) responsável pela prestação de serviços. A evolução dos tipos é de acordo com o tempo de existência e amadurecimento por parte do CSC e da gestão da organização. O Quadro 3 resume os modelos citados.

Quadro 3: Tipos de Centros de Serviços Compartilhados

\begin{tabular}{|c|c|c|c|c|}
\hline Modelo & Básico & Marketplace & $\begin{array}{c}\text { Marketplace } \\
\text { Avançado }\end{array}$ & $\begin{array}{c}\text { Empresa } \\
\text { Independente }\end{array}$ \\
\hline Características & $\begin{array}{c}\text { Consolidação } \\
\text { das } \\
\text { transações e } \\
\text { atividades de } \\
\text { apoio }\end{array}$ & $\begin{array}{c}\text { Inclui o } \\
\text { fornecimento } \\
\text { de serviços } \\
\text { especializados } \\
\text { e consultoria }\end{array}$ & $\begin{array}{c}\text { O cliente } \\
\text { escolhe seu } \\
\text { fornecedor }\end{array}$ & $\begin{array}{c}\text { Várias empresas } \\
\text { clientes }\end{array}$ \\
\hline
\end{tabular}




\begin{tabular}{|c|c|c|c|c|}
\hline & $\begin{array}{l}\text { Economia de } \\
\text { escala }\end{array}$ & $\begin{array}{c}\text { Organização } \\
\text { estrutura } \\
\text { a própria } \\
\text { governança }\end{array}$ & $\begin{array}{c}\text { Fornecimento } \\
\text { de serviços } \\
\text { com o repasse } \\
\text { dos custos } \\
\end{array}$ & $\begin{array}{c}\text { Objetivo é o lucro } \\
\text { com a prestação } \\
\text { dos serviços }\end{array}$ \\
\hline Características & $\begin{array}{l}\text { Os custos } \\
\text { dos serviços } \\
\text { não são } \\
\text { repassados } \\
\text { aos clientes } \\
\text { internos. }\end{array}$ & $\begin{array}{l}\text { Custos } \\
\text { totalmente } \\
\text { repassados } \\
\text { para as } \\
\text { unidades de } \\
\text { negócio }\end{array}$ & $\begin{array}{c}\text { Possibilidade } \\
\text { de venda } \\
\text { de serviços } \\
\text { a clientes } \\
\text { externos, se } \\
\text { a capacidade } \\
\text { produtiva for } \\
\text { excedente }\end{array}$ & $\begin{array}{c}\text { Atuação como } \\
\text { empresa } \\
\text { independente }\end{array}$ \\
\hline Objetivo & $\begin{array}{c}\text { Reduzir } \\
\text { custos e } \\
\text { padronizar os } \\
\text { processos de } \\
\text { produção dos } \\
\text { serviços }\end{array}$ & $\begin{array}{l}\text { Reduzir custos } \\
\text { e melhorar a } \\
\text { qualidade dos } \\
\text { serviços }\end{array}$ & $\begin{array}{c}\text { Fornecer } \\
\text { a melhor } \\
\text { alternativa } \\
\text { em custos dos } \\
\text { serviços }\end{array}$ & $\begin{array}{c}\text { Gerar receitas } \\
\text { e lucro como } \\
\text { uma empresa } \\
\text { de prestação de } \\
\text { serviços }\end{array}$ \\
\hline $\begin{array}{c}\text { Forma de } \\
\text { relacionamento }\end{array}$ & $\begin{array}{c}\text { Utilização } \\
\text { compulsória } \\
\text { dos serviços } \\
\text { pelas } \\
\text { unidades de } \\
\text { negócio }\end{array}$ & $\begin{array}{l}\text { Utilização } \\
\text { voluntária }\end{array}$ & $\begin{array}{l}\text { Utilização } \\
\text { voluntária }\end{array}$ & $\begin{array}{l}\text { Utilização } \\
\text { voluntária }\end{array}$ \\
\hline
\end{tabular}

Fonte: Quinn, Cookie e Kris (2000).

No modelo básico, o CSC foca no cliente interno, prestando serviços às unidades de negócio que acionam o CSC de forma compulsória. Todos os custos dos serviços prestados não são repassados para os clientes internos, ou seja, não há uma precificação para cada tipo de serviço executado pelo CSC. O foco aqui é economia de escala com a padronização dos processos, mantendo a qualidade do serviço prestado (QUINN; COOKE; KRIS, 2000).

No modelo marketplace, há um modelo de governança responsável por criar acordos de níveis de serviços (ANS) com o objetivo de padronizar, controlar e operacionalizar os serviços prestados. É possível a terceirização de algumas atividades com a finalidade de auxiliar o atendimento da demanda total. Os custos são repassados para os clientes internos, mas nesse modelo eles não possuem a obrigatoriedade de utilizar o CSC (QUINN; COOKE; KRIS, 2000).

No modelo marketplace avançado, as unidades de negócios podem escolher entre um serviço prestado pelo CSC ou um serviço prestado por um 
terceiro. Os preços dos serviços são definidos pelo valor de mercado e devem ser competitivos, visto que as unidades de negócios podem comparar para escolher a melhor opção. Nesse modelo também é possível que o CSC venda os seus serviços para outras organizações (QUINN; COOKE; KRIS, 2000).

Já o modelo empresa independente é a última fase e, por isso, aqui o CSC é visto como uma unidade independente. Ou seja, vira uma empresa prestando serviços a diversos clientes e gerando lucro para a organização (QUINN; COOKE; KRIS, 2000).

Para Magalhães (2018), em termos de alocação do CSC na organização, há pelo menos quatro modelos hierárquicos possíveis, conforme mostrado no Quadro 4.

Quadro 4: Modelos hierárquicos de CSC

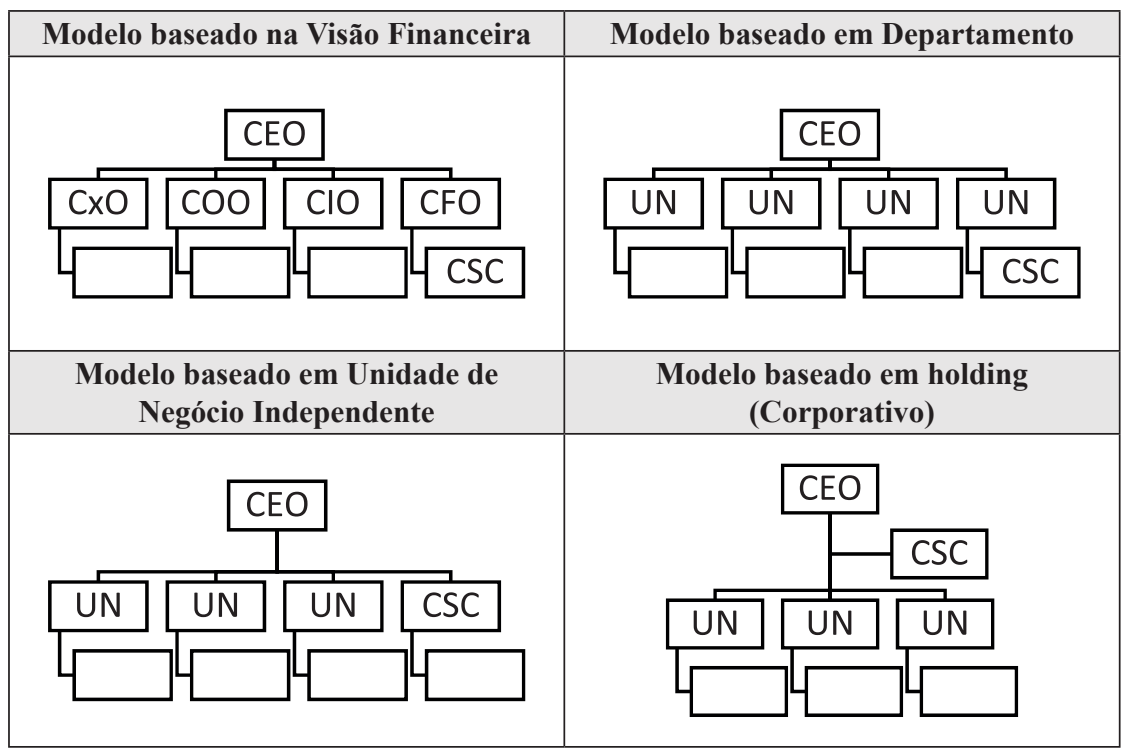

Fonte: Magalhães (2018).

O primeiro modelo é quando o CSC é subordinado hierarquicamente ao diretor financeiro (CFO). Entre os prós podemos destacar o alto controle financeiro, a boa gestão de números, o foco em controle e o foco em redução de custos. Já o pouco foco em demais áreas migradas para o CSC, o pouco desenvolvimento do CSC e o alto processo de terceirização são vistos como contras (MAGALHÃES, 2018). 
O modelo baseado em departamento é quando o CSC é subordinado hierarquicamente a uma unidade de negócio (UN). A utilização do conhecimento da unidade escolhida e a padronização baseada no modelo da UN são vantagens desse modelo. Como desvantagens, podemos citar a equipe subordinada a UN em que atua e não à corporação, os conflitos entre os gestores, a segregação de função e a alta resistência ao modelo (MAGALHÃES, 2018).

O terceiro modelo é quando o CSC é subordinado hierarquicamente ao presidente da empresa (CEO). A independência de gestão, o foco em desenvolvimento do negócio, o foco em suporte ao cliente e em melhoria contínua para sobreviver às mudanças do negócio são os benefícios desse modelo, enquanto o alto investimento inicial e a resistência dos gestores são as desvantagens (MAGALHÃES, 2018).

O último modelo, também conhecido como modelo baseado em holding, está na estrutura organizacional como staff assessorando a organização como um todo, mas tendo autonomia em relação a ela. $\mathrm{O}$ foco em controle do negócio, a baixa resistência dos gestores e o foco em serviços de gestão de desempenho/ relatórios corporativos são os prós. O pouco foco em desenvolver áreas que geram valor ao negócio e a tendência do CSC em se desenvolver como controladoras são consideradas como contras (MAGALHÃES, 2018).

\section{PROCEDIMENTOS METODOLÓGICOS}

Essa pesquisa pode ser classificada como aplicada, qualitativa e descritiva. A pesquisa quanto à sua natureza é aplicada, visto que seu objetivo é voltado para a aplicação prática (GERHARDT; SILVEIRA, 2009), e assim gerar conhecimentos dirigidos à solução de problemas específicos, como a escolha do tipo de CSC a ser instalado e os riscos associados. Por outro lado, a abordagem é qualitativa, pois existe a necessidade da investigação se desenvolver em uma ótica predominantemente compreensiva e interpretativa (CRESWELL, 2007), de como as decisões relacionadas ao CSC foram tomadas na empresa foco do estudo.

Já uma pesquisa descritiva tem como objetivo a investigação da natureza da relação entre variáveis e a descrição de características (GIL, 2008). Diante disso, quanto aos objetivos, a pesquisa trata-se de descritiva porque procura descrever as estruturas organizacionais existentes na literatura de um CSC e a escolhida no estudo de caso.

A pesquisa bibliográfica e o estudo de caso foram os procedimentos metodológicos escolhidos para essa pesquisa. Na pesquisa bibliográfica foi feita 
uma revisão sistemática da literatura, com busca em livros e artigos das bases SPELL, SciELO, Portal de Periódicos da Capes, Web of Science e Scopus.

Já o estudo de caso é único, sendo que esse tipo é comumente utilizado para validação de proposições, contribuição à construção de novas teorias e redirecionamento de investigações futuras (YIN, 2001). Nessa pesquisa, a empresa de tecnologia e serviços foi escolhida por conveniência em função da autora principal desse trabalho ter tido a oportunidade de observar e analisar o fenômeno de implementação de um CSC.

A organização estudada (Empresa A) é nacional e de grande porte, parceira estratégica de um banco, e presta serviços para ele e suas coligadas. Está há 45 anos no mercado, presente em 44 cidades de 23 estados, e tem 3.287 empregados.

As questões do estudo foram definidas como: Quais motivações e riscos estão associados à implementação de um CSC? Quais as vantagens e desvantagens associados aos diferentes tipos/modelos organizacionais de CSC? Nesse sentido, no estudo de caso, consideraram-se como unidade de análise, as vantagens e desvantagens da estrutura organizacional (modelo) de CSC escolhida, e como subunidade, as motivações/ riscos associados à criação do CSC. Uma subunidade que surgiu no decorrer das entrevistas foram os ganhos obtidos pela empresa A com a implementação do CSC, e por isso ela foi considerada na apresentação dos resultados.

No estudo de caso, para entender a percepção da equipe do projeto, foram realizadas entrevistas semiestruturadas com os seguintes colaboradores: gerente do projeto (1), o assessor/ implementador do CSC (1), o assessor/ gerente do CSC (1), e a equipe do projeto (4). O Quadro 5 apresenta o perfil dos entrevistados.

Quadro 5: Perfil dos Entrevistados

\begin{tabular}{|c|c|c|c|c|c|}
\hline No. & $\begin{array}{c}\text { Cargo no } \\
\text { Projeto }\end{array}$ & Sexo & Idade & $\begin{array}{c}\text { Escolaridade/ } \\
\text { Formação }\end{array}$ & $\begin{array}{c}\text { Tempo de } \\
\text { Experiência } \\
\text { profissional }\end{array}$ \\
\hline A1 & $\begin{array}{c}\text { Gerente do } \\
\text { Projeto CSC }\end{array}$ & Masculino & 58 & $\begin{array}{c}\text { Doutorando em } \\
\text { Engenharia de } \\
\text { Produção. Mestre } \\
\text { e Graduado em } \\
\text { Engenharia de } \\
\text { Produção. }\end{array}$ & 35 anos \\
\hline
\end{tabular}




\begin{tabular}{|c|c|c|c|c|c|}
\hline $\mathrm{A} 2$ & $\begin{array}{c}\text { Assessor/ } \\
\text { Implementador } \\
\text { do CSC }\end{array}$ & Masculino & 73 & $\begin{array}{l}\text { Graduado em } \\
\text { Economia. }\end{array}$ & 53 anos \\
\hline A3 & $\begin{array}{c}\text { Assessor/ } \\
\text { Gerente do } \\
\text { CSC }\end{array}$ & Masculino & 58 & $\begin{array}{l}\text { Pós-Graduado em } \\
\text { Gerenciamento de } \\
\text { Projetos. Graduado } \\
\text { em Administração e } \\
\text { Direito. }\end{array}$ & 33 anos \\
\hline A4 & $\begin{array}{l}\text { Analista / } \\
\text { Especialista } \\
\text { (equipe do } \\
\text { projeto) }\end{array}$ & Masculino & 44 & $\begin{array}{l}\text { Pós-Graduado em } \\
\text { Educação Tecnológica. } \\
\text { Graduado em Gestão } \\
\text { Financeira, Matemática } \\
\text { e Eletrônica. }\end{array}$ & 30 anos \\
\hline A5 & $\begin{array}{l}\text { Técnico de } \\
\text { Operações } \\
\text { (equipe do } \\
\text { projeto) }\end{array}$ & Masculino & 30 & $\begin{array}{l}\text { Pós-Graduado em } \\
\text { Gerenciamento de } \\
\text { Projetos. Graduado } \\
\text { em Engenharia de } \\
\text { Produção. }\end{array}$ & 5 anos \\
\hline A6 & $\begin{array}{l}\text { Técnico de } \\
\text { Operações } \\
\text { (equipe do } \\
\text { projeto) }\end{array}$ & Masculino & 26 & $\begin{array}{c}\text { Graduando em } \\
\text { Engenharia de } \\
\text { Produção. } \\
\text { Graduado em Gestão } \\
\text { da Produção Industrial. }\end{array}$ & 6 anos \\
\hline A7 & $\begin{array}{l}\text { Técnico de } \\
\text { Operações } \\
\text { (equipe do } \\
\text { projeto) }\end{array}$ & Masculino & 32 & $\begin{array}{c}\text { Graduando em } \\
\text { Administração. } \\
\text { Pós-Graduado em } \\
\text { Gestão Integrada de } \\
\text { QSMS. } \\
\text { Graduado em Ciências } \\
\text { Biológicas. }\end{array}$ & 6 anos \\
\hline
\end{tabular}

Fonte: Elaborado pelos autores.

O gerente do projeto teve a missão de gerenciar o projeto por 6 meses, garantindo a entrega do plano do CSC dentro do prazo e previstos. À equipe do projeto (analistas e técnicos) foram atribuídas as ações do projeto, inclusive ferramentas para coleta e análise dos dados obtidos. Os assessores, durante a fase do projeto, ficaram responsáveis por coordenar a equipe do projeto e as ações a ela atribuídas. Após os 6 meses de projeto, um assessor ficou responsável por implementar o CSC, colocando em prática tudo o que foi previsto no projeto, e o outro se tornou o gerente da operação uma vez implementado.

Ademais, pelo fato de a autora principal desse trabalho ter sido integrante 
do projeto de planejamento do CSC, pode-se considerar que o procedimento da observação participante também foi utilizado. Além disso, foi utilizada a pesquisa documental, pois foi realizada uma análise dos documentos internos da empresa estudada (relatório final, organograma, formulário de processo, documento de requisito de $\mathrm{TI}$, acordo de nível de serviço etc.).

Por fim, a análise de dados foi realizada a partir da técnica de análise de conteúdo, que foi realizada nos documentos organizacionais, nas transcrições das entrevistas e nas anotações das observações realizadas.

\section{ANÁLISE E DISCUSSÃO DOS RESULTADOS}

\subsection{Motivações e riscos associados à criação do CSC}

A empresa A identificou a necessidade de mudança na sua estrutura organizacional e decidiu por ter um CSC. O Quadro 6 apresenta uma síntese das motivações mais citadas pelos entrevistados, em ordem decrescente, para criação do CSC.

Quadro 6: Motivações para implementação do CSC

\begin{tabular}{|c|c|}
\hline Motivações & Citações \\
\hline Desoneração das áreas estratégicas & 2 \\
\hline Produtividade & 2 \\
\hline Redução de custos & 1 \\
\hline Agilidade na prestação do serviço & 1 \\
\hline Qualidade na prestação do serviço & 1 \\
\hline Definição dos níveis de planejamento & 1 \\
\hline
\end{tabular}

Fonte: Elaborado pelos autores.

Quando comparado com a literatura, motivações como desoneração das áreas estratégicas, produtividade, redução de custos e qualidade na prestação do serviço são também mencionadas por autores como Janssen e Joha (2006), Magalhães (2018), Reilly e Williams (2003), Silva e Pereira (2004) e Ulrich (1995). O termo "agilidade na prestação do serviço" não foi encontrado exatamente na literatura, porém é possível considerar que a produtividade gera uma melhoria no atendimento, e a Deloitte (2017) indica a agilidade na aquisição da área de compras como um motivador. Diante do exposto, a única motivação do caso que não foi encontrada na literatura foi a definição dos níveis 
de planejamento em estratégico, tático e operacional.

\subsection{Ganhos obtidos com criação do CSC}

Em termos de ganhos obtidos, todos os entrevistados responderam positivamente quando foram indagados sobre o ganho no tempo dos gestores para se dedicar aos processos estratégicos após a criação do CSC. "O dono do processo sim, ele se viu livre de amarras operacionais para que pudesse efetivamente tocar parte estratégica do processo de uma forma muito mais leve, muito mais suave...aí sim.... maior qualidade..." (Entrevistado A3).

Outro ganho obtido com a criação do CSC pela empresa A, confirmado por todos os entrevistados, foi a aproximação do CSC com as áreas clientes. A aproximação foi tanta, conforme relatado por um entrevistado, que o cliente interno passou a procurar o CSC até para resolver questões ou tirar dúvidas que não são da competência dele. De qualquer, o CSC procura sempre ajudar, dentro dos seus limites, pensando que aquela contribuição é significativa para a empresa. Há uma relação de confiança e dependência.

O entrevistado A6 apontou que "Houve uma aproximação do CSC com cliente interno, pois o cliente passou a depender dos serviços do CSC para poder tocar seus processos. Então, houve sim essa aproximação... Acredito que houve ganhos, pequenos ganhos obtidos em alguns processos".

A prestação do serviço foi melhorada. Esse acompanhamento é feito através da pesquisa de satisfação que o funcionário da área cliente responde após a conclusão do chamado no sistema de atendimento interno do CSC. Esse sistema também gera relatórios gerenciais da operação, com informações, como por exemplo, de tempo médio de atendimento do chamado. "Sim, em alguns serviços a gente conseguiu melhorar muito o tempo de atendimento, a qualidade no atendimento..." (Entrevistado A5).

Com relação aos custos, não houve uma mensuração da redução por processo na época do projeto piloto. Todavia, os entrevistados acreditam que houve uma possível redução, devido à falta de reposição dos funcionários que saíram do CSC e as atividades que foram migradas sem transferência de pessoal. O entrevistado A2 disse que "Quanto é difícil mensurar, mas que houve redução de custos eu não tenho dúvida". E o entrevistado A5 informou "A gente teve uma redução de 8 funcionários e a gente conseguiu manter o nível operacional, e o atendimento das demandas porque os funcionários não foram substituídos. Tiveram algumas atividades que foram migradas sem funcionários. Isso também acabou gerando uma redução de custos".

De uma maneira geral, dentre as contribuições positivas do CSC para a organização, os funcionários elencaram os seguintes: padronização e 
conformidade das atividades; utilização, mesmo que não intensiva, da tecnologia; otimização dos processos; agilidade na prestação do serviço e processos que não eram de conhecimento do funcionário e passaram a ter maior visibilidade no CSC. Dois entrevistados expuseram opiniões interessantes sobre os ganhos com a concentração das atividades:

Digamos que eu acho que de todas as questões... Você está centralizando e colocando no mesmo espaço atividades que se conectam diretamente. Antes a gente tinha um macroprocesso que estava ali, cada um pendurado em uma área diferente, e tendo tudo na mesma área vai dar uma otimização, as pessoas vão ter um diálogo. Vai ser tudo muito mais ... Vai ter uma celeridade. Então, eu acho que esse é um ganho muito importante... (Entrevistado A7).

Houve uma melhor organização dos processos que possuem grande volume de solicitações e que por muitas vezes estavam espalhados pela empresa em áreas que não necessariamente deveriam contê-las. Então elas foram setorizadas de forma a ficarem melhor organizadas. Funcionando mais automatizadas, fazendo com que pudessem ser criados relatórios de satisfação de cliente e um maior controle de resultados (Entrevistado A6).

O Quadro 7 apresenta uma síntese dos ganhos mais citados pelos entrevistados, em ordem decrescente.

Quadro 7: Síntese dos Ganhos Obtidos com a criação do CSC

\begin{tabular}{|c|c|}
\hline Ganhos Obtidos & Citações \\
\hline Redução de custos & 4 \\
\hline Agilidade na prestação do serviço & 4 \\
\hline Otimização dos processos & 3 \\
\hline Padronização e conformidade das atividades & 3 \\
\hline Utilização, mesmo que não intensiva, da tecnologia & 2 \\
\hline Ganho no tempo dos gestores para se dedicar ao estratégico & 2 \\
\hline Visibilidade dos processos & 1 \\
\hline
\end{tabular}

Fonte: Elaborado pelos autores. 


\subsection{Vantagens e desvantagens do modelo de CSC escolhido}

Após a implementação do CSC, foi criada a Gerência de Centro de Serviços Compartilhados, que ficou hierarquicamente abaixo da Gerência de Serviços Internos, e que por sua vez está vinculada à Gerência de Administração, conforme demonstrado na Figura 3.

Figura 3: Alocação do CSC na estrutura organizacional da Empresa A

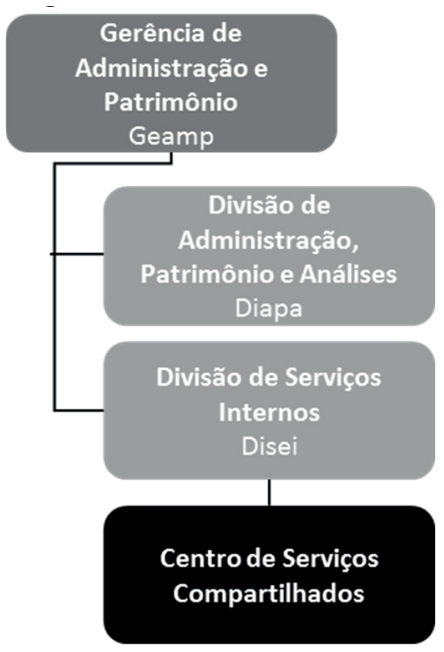

Fonte: Adaptado pelos autores a partir de Empresa A

Os serviços da Empresa A são compartilhados entre áreas de uma mesma organização e por isso, de acordo com a classificação de Janssen e Joha (2006) podem ser chamados de intraorganizacional (JANSSEN; JOHA, 2006).

Ao mesmo tempo, o CSC foi projetado para ser do tipo Back Office, ou seja, com pouco ou nenhum contato com o cliente externo (PETRIŞOR; COZMIUC, 2016). A criação ocorreu dessa forma, pois não há necessidade de contato com o único cliente externo, que é o banco. Quando perguntado sobre isso um dos entrevistados respondeu: "Back Office, a gente não tem praticamente contato nenhum. Uma coisa ou outra quando a gente vai agendar férias de funcionários cedidos. Fora isso, praticamente zero" (Entrevistado A5).

Entre os 4 tipos apresentados por Quinn, Cooke e Kris (2000), o CSC da empresa A se enquadra no primeiro, o básico. No modelo básico, o CSC foca no cliente interno, prestando serviço às unidades de negócio que acionam o 
CSC de forma compulsória e não há uma precificação para cada tipo de serviço executado pelo CSC.

Foi observado que o CSC da empresa A, por ter sido implementado em 2016 (relativamente recente) e ainda estar absorvendo atividades operacionais, não repassa os seus custos (não há precificação dos serviços prestados) para os clientes internos. Ademais, como a estrutura foi criada com atividades que foram migradas de departamentos internos, como a atividade de arquivo geral do departamento de administração, por exemplo, o serviço se tornou compulsório por parte dos clientes internos. Ou seja, se as áreas internas quiserem o serviço de arquivo geral, elas compulsoriamente precisam solicitar ao CSC este tipo de serviço.

A estrutura organizacional escolhida pela organização se enquadra no modelo hierárquico baseado em departamento conforme apresentado por Magalhães (2018). Esse modelo traz como prós o conhecimento utilizado da unidade escolhida e padronização baseada no modelo da unidade. Nesse tipo de estrutura, o CSC vai fazer parte de uma unidade de negócio já possui expertise nas suas atividades e padrões estabelecidos de acordo com a empresa, o que pode contribuir inicialmente para a gestão do CSC.

Todavia, os contras são: 1) equipe subordinada à unidade em que atua e não à corporação; e 2) alta resistência ao modelo. Essas desvantagens foram comprovadas no estudo de caso realizado.

1) O CSC não tem autonomia. Todos os entrevistados responderam que não há autonomia. Isso ocorre pelo fato de o CSC estar ligado diretamente ao departamento de Administração, e porque as áreas responsáveis pelas atividades migradas continuarem como donas desses processos. "Não, porque quem é o responsável continua sendo a área estratégica e não o CSC. A gente é responsável apenas pela operação" (Entrevistado A4).

A intenção era que as áreas clientes ficassem responsáveis pelos normativos e gente ficaria pela definição dos procedimentos. Então, a gente teria essa liberdade de alterar os procedimentos conforme as necessidades de padronização do processo e a gente consultaria a área cliente para ver se eles teriam algum problema, mas a gente teria uma autonomia maior do que a gente tem hoje. Hoje não é assim, a gente não consegue mexer em procedimento livremente. A gente tem que pedir para eles alterarem, a gente até em informa o que a gente gostaria, mas a gente não consegue mexer. Eles que mexem. A gente fica dependente deles (Entrevistado A5). 
2) Os Gestores estavam resistentes e não queriam se desapegar de seus processos com medo de possíveis perdas.

Resistência das áreas em repassar o procedimento. Tinha uma resistência muito grande, eles queriam segurar o processo o máximo maior tempo possível, e até dificultar para ver se fracassava, porque eles entendiam que seria uma perda de poder, um risco de afetar a área e até poder, de repente, acabar com algumas áreas... (Entrevistado A5).

\section{CONCLUSÃO}

Inicialmente buscou-se pesquisar sobre as motivações e riscos associados à estratégia de CSC assim como as estruturas organizacionais/modelos de CSC existentes na literatura e após isso foi realizada uma análise comparativa das teorias com o estudo de caso da empresa A.

No caso analisado, as motivações e potenciais riscos apontados, que justificam a existência do CSC, foram respectivamente: desoneração das áreas estratégicas; produtividade; redução de custos; agilidade na prestação do serviço; qualidade na prestação do serviço; e definição dos níveis de planejamento. Já os ganhos identificados após a implementação do CSC foram respectivamente: redução de custos; agilidade na prestação do serviço; otimização dos processos; padronização e conformidade das atividades; utilização, mesmo que não intensiva, da tecnologia; ganho no tempo dos gestores para se dedicar ao estratégico; visibilidade dos processos.

Em termos de tipos/ modelos de CSC, a empresa A optou por um CSC do tipo intraorganizacional, back office e básico, e o modelo hierárquico baseado em departamento, sendo esse vinculado à Gerência de Administração. Esse modelo tem como prós o conhecimento utilizado da unidade escolhida e padronização baseada no modelo da unidade. Todavia, os contras são a equipe subordinada a unidade de negócio que está vinculada, e não à corporação, e alta resistência ao modelo. Essas vantagens e desvantagens foram comprovadas no estudo de caso realizado.

Entende-se que a definição do modelo e estrutura do CSC é uma decisão interna e de acordo com a cultura da organização. Todavia, ressalta-se a importância do alinhamento estratégico da organização com o tipo de CSC 
escolhido, e de se discutir a autonomia que o CSC pretende ter.

Dentre as possíveis limitações da pesquisa, destacam-se: a utilização do procedimento de estudo de caso único em uma empresa de tecnologia e serviços de grande porte, dificultando a generalização dos resultados; o fato de algumas informações (documentos) não estarem disponíveis aos pesquisadores ou a necessidade de serem omitidas durante a apresentação dos resultados por questão de confidencialidade da organização estudada; e a existência de uma literatura limitada sobre CSC.

Sugerem-se como futuras pesquisas a replicação do trabalho com novos estudos de casos ou mesmo o levantamento de dados via survey, assim como um aprofundamento da temática de modelos/ estruturas organizacionais de CSC, pois é um tema pouco discutido na literatura.

\section{REFERÊNCIAS}

BERGERON, B. Essentials of shared services. Nova Jersey: John Wiley and Sons, 2003. $272 \mathrm{p}$.

CRESWELL, J. W. Projeto de pesquisa: métodos qualitativo, quantitativo e misto. 2. ed. Porto Alegre: Artmed, 2007. 248 p.

DELOITTE. Pesquisa Global de Serviços Compartilhados 2017. São Paulo, 2017. Disponível em: < https://www2.deloitte.com/br/pt/pages/operations/ articles/global-shared-services-survey.html> Acesso em: 21 de jun. 2017.

EMPRESA A. Projeto CSC - Relatório Final. Rio de Janeiro, 2015.

FORST, L. The evolution of the shared services business unit. Performance Improvement, Maryland, v. 39, n. 8, p. 8-17, 2000.

GERHARDT, T. E.; SILVEIRA, D. T. Métodos de pesquisa. 1. ed. Porto Alegre: Editora da UFRGS, 2009. 120p.

GIL, A. C. Métodos e técnicas de pesquisa social. 6. ed. São Paulo: Atlas, 2008. 200p

JANSSEN, M.; JOHA, A. Understanding IT governance for the operation of shared services in public service networks. International Journal of Networking and Virtual Organisations, [S.L.], v. 4, n. 1, p. 20-34, 2007. 
. Motives for establishing shared service centers in public administrations. International Journal of Information Management, [S.L.], v. 26, n. 2, p. 102-115, 2006.

LOZINSKY, S. Serviços compartilhados como melhor prática. IBM Global Business Services, São Paulo, 2006.

MAGAlHÃES, C. Centro de Serviços Compartilhados. 2. ed. São Paulo: All Print, 2018. 320p.

MINNAAR, R. A.; VOSSELMAN, E. G. J. Shared service centres and management control structure change: Exploring the scope and limitations of a transaction cost economics approach. Journal of Accounting \& Organizational Change, [S.L.], v. 9, n. 1, p. $74-98,2013$.

NATIONAL AUDIT OFFICE (NAO). Improving corporate functions using shared services: Report by the Comptroller and Auditor General. London, 2007. Disponível em: $<$ https://www.nao.org.uk/report/improving-corporatefunctions-using-shared-services/> Acesso em: 18 set. 2018.

PETRIŞOR, I.; COZMIUC, D. Specific Business Models for Romanian Companies-Shared Services. Procedia-Social and Behavioral Sciences, [S.L.], v. 221, 2016. p. 151-158.

PORTER, M. E. Competição: estratégias competitivas essenciais. 13. ed. Rio de Janeiro: Campus, 1999. 515p.

REILLY, P. HR Shared Services and the Realignment of HR. Brighton: The Institute For Employment Studies, v. 368, 2000.

REILLY, P.; WILLIAMS, T. How to get best value from HR: The shared services option. Aldershot: Gower Publishing Limited,v. 566, 2003.

QUINN, B.; COOKE, R.; KRIS, A. Shared Services: Mining for Corporate Gold. London: Financial Times Prentice Hall, 2000. 256p.

SCHULMAN, D. S. et al. Serviços Compartilhados: agregando valor às unidades de negócios. São Paulo: Makron Books, 2001. 280p.

SILVA, E. D. da; PEREIRA, N. A. F. Centro de serviços compartilhados e a gestão de vínculos: uma análise integrada. Revista Alcance, Biguaçu, v. 11, n. 
1, p. $49-64,2004$.

SINGH, P. J.; CRAIKE, A. Serviços compartilhados: para uma definição conceitual mais holística. Revista Internacional de Sistemas de Informação de Negócios, [S.L.], v. 3, n. 3, p. 217-230, 2008.

ULBRICH. Introducing a Research Project on Shared Services in Governmental Agencies. In: 17th Scandinavian Academy of Management (NFF) Conference. Anais... Reykjavik, Iceland. 14-16 ago. 2003.

ULRICH, D. Shared services: From vogue to value. People and Strategy, [S.L.], v. 18, n. 3, p. 12, 1995.

YIN, R. K. Estudo de Caso: Planejamento e Métodos. 2. ed. Porto Alegre: Bookman, 2001. 207p. 
